ISSN 2526-7248 artigo n. 3SPPC2018, pp. 198-208, 2018

\title{
Manifestações patológicas decorrentes da má utilização da fôrma de madeira na Região Metropolitana do Recife
}

Salgado, Antônio Eugênio Barcelos Viana ${ }^{1}$; Nascimento, Carlos Fernando Gomes 2. Nascimento, Nicole Pâmela da Silva ${ }^{3 ;}$ Santos, Manueli Suêni da Costa ${ }^{4}$; Souza, Dandara Vitória Santana ${ }^{5}$; Monteiro, Eliana Cristina Barreto ${ }^{6}$.

${ }^{1}$ Engenhario Civil, Univ. Católica de Pernambuco

${ }^{2}$ Graduando, Univ. Católica de Pernambuco, carlosfernando.gn@gmail.com

${ }^{3}$ Mestranda, Univ. Católica de Pernambuco, nicolenascimentoeng@gmail.com

${ }^{4}$ Graduanda, Univ. Católica de Pernambuco, manuelisueni@hotmail.com

${ }^{5}$ Graduanda, Univ. Católica de Pernambuco, dandasantana@outlook.com

${ }^{6}$ Professora, Univ. de Pernambuco e Univ. Católica de Pernambuco, eliana@poli.br

Resumo: As fôrmas de madeira são bastante utilizadas difundindo sua importância na construção civil, frente ao desenvolvimento de empreendimentos de grande e pequeno porte com funções específicas nas edificações. Elas garantem o alinhamento da construção quando utilizadas para moldagem, mantendo sua geometria desde pilares, vigas, até mesmo nas proteções e delimitações de canteiros para melhor desenvolvimento. Mesmo a utilização de fôrmas de madeiras sendo um sistema largamente difundido, é comum encontrar falhas no seu manuseio, causando desalinhamentos e embuchamento de peças estruturais. Falhas causadas em muitos casos pelo empirismo e em outros casos pela falta de fiscalização da equipe gestora da obra. Nessa pesquisa foram visitados três empreendimentos da Região Metropolitana do Recife, tendo como objetivo listar as principais falhas e suas subsequentes manifestações patológicas, propondo assim, medidas de prevenção para evitar a reincidência dessas falhas no setor e contribuir para contínua melhora do sistema construtivo brasileiro. Foram encontradas manifestações patológicas como desaprumo em peças de concreto e presença de cavidades devido a saliência e ondulações presentes nas fôrmas. Conclui-se que um projeto de sistema de fôrmas dimensionado e elaborado da forma correta unido a uma fiscalização adequada durante a montagem e desfôrma é capaz de evitar as manifestações patológicas mais comuns decorrentes dos sistemas de fôrmas de madeira.

Palavras-chave: Fôrmas de madeira, manifestações patológicas, medidas de prevenção, empreendimentos, Região Metropolitana do Recife.

\begin{abstract}
The forms of wood are widely used, spreading their importance in the civil construction, in front of the development of large and small enterprises with specific functions in the buildings. It guarantees the alignment of the construction when used for molding, maintaining its geometry from pillars, beams, even on the protections and delimitations of beds for better development. Even the use of wood forms is a widespread system, it is common to find fault in its handling, causing misalignment and packing of structural parts. Failures caused in many cases by empiricism and in other cases by the lack of supervision of the management team of the work. In this research three projects of the Metropolitan Region of Recife were visited, aiming at listing the main faults and their subsequent pathological manifestations, thus proposing preventive measures to avoid recurrence of these failures in the sector, contributing to the continuous improvement of the Brazilian construction system. Pathological manifestations like disappearance in concrete pieces and presence of cavities due to the prominence and undulations present in the forms were found. It is concluded that a design of a correctly dimensioned and elaborated form system coupled with adequate inspection during assembly and dismantling is able to avoid the most common pathological manifestations resulting from the systems of wood forms.
\end{abstract}

Keywords: Wood forms, pathological manifestations, prevention measures, entrepreneurship, Metropolitan Region of Recife. 


\section{Introdução}

Segundo a NBR 15696:2009 [1], as fôrmas são "estruturas provisórias utilizadas para moldar o concreto fresco, resistindo a todas as ações provenientes das cargas variáveis resultantes das pressões do lançamento do concreto fresco até que o concreto se torne autoportante".

Azevedo (2008) apud Müller (2016) [3] afirma que a fôrma é um dos subsistemas que compõem o grupo construtivo, em prol das necessidades do empreendimento. Todos estes subsistemas contribuem para o resultado do conjunto. Ainda nos conceitos do autor, a fôrma tem uma particularidade única dentro deste cenário, que é iniciar todo o processo, e por isso, passa a ser a referência para os demais, estabelecendo e padronizando a exigência para a obra. $O$ autor relata ainda que 0 desempenho do sistema de fôrma exerce forte influência na qualidade, prazo e custo do empreendimento.

Em Recife, a maior parte das obras são executadas em concreto armado moldado inloco, sendo o uso de fôrmas e escoramentos indispensável para este tipo de empreendimento. No mercado brasileiro, estão disponíveis vários tipos de fôrmas, sendo possível locar, montar na obra ou comprar, a depender das condições da obra.

De acordo com Nazar (2007) [4], a importância das fôrmas de concreto na concepção, na execução e nos custos da estrutura de um edifício justifica plenamente um estudo detalhado do seu dimensionamento e a melhor escolha dos materiais, o que acabará refletindo na mão de obra e nos demais itens, mesmo aqueles não diretamente ligados à estrutura de concreto armado. Partindo deste ponto o estudo de manifestações patológicas decorrentes do mau uso destes materiais torna-se necessária ao setor construtivo do Recife.

A deficiência de informação sobre este tema na formação de engenheiros civis é o passo inicial para explicar a falta de interesse em um item tão importante em todo o processo construtivo de um edifício, afirma Nazar [4].

$\mathrm{Na}$ construção civil geralmente se deixa para os encarregados e mestres de obras a responsabilidade referente à definição das fôrmas, acreditando que o conhecimento prático para o dimensionamento fosse o suficiente para garantir a estabilidade das mesmas. Com isso, não se leva em consideração os custos decorrentes da falta de um rigor maior para o trato desse material.

Porém, com o alto custo da madeira, existe a necessidade de ter uma maior atenção a este requisito. Mesmo com conceitos bem difundidos na cultura da construção pernambucana sobre fôrmas, ainda é possível encontrar falhas que ocorrem na concepção do projeto da fôrma até a execução da montagem.

Uma equipe experiente junto a um projeto bem feito é essencial quando se quer executar a concretagem sem que ocorra o desaprumo das peças, deformação e perca do alinhamento, cavidades devido a assaliências, dentre outras manifestações patológicas decorrentes da má utilização de fôrmas. 
O objetivo desta pesquisa é listar as principais falhas e suas subsequentes manifestações patológicas, em três edifícios do Recife, propondo assim, medidas de prevenção para evitar a reincidência dessas falhas no setor.

Este trabalho justifica-se pela necessidade de identificar os principais erros cometidos no que se refere ao uso de fôrmas e escoramentos, para uma melhor conscientização de todas as partes envolvidas no processo. Além de somar conhecimento ao uso desses materiais tão importantes na indústria e no mercado da construção civil brasileira.

\section{Revisão bibliográfica}

\subsection{Definição de madeira}

Conforme Costa apud Rodrigues e Sales (2013) [6], a madeira é um produto do tecido xilemático dos vegetais superiores, localizado em geral no tronco e galhos das árvores, com células especializadas na sustentação e condução de seiva. Do ponto de vista comercial, a madeira somente é encontrada em árvores com altura superior a 6 metros.

Moreschi (2012) [2] informa que as propriedades organoléticas da madeira são aquelas que impressionam os órgãos sensitivos, sendo elas: cor, grã, textura e desenho que se apresentam no material, bem como odor e sabor, e são diretamente ligadas ao seu valor decorativo e ornamental, e aos usos onde o cheiro e gosto de produtos armazenados ou embalados com a madeira possam ser alterados.

Nazar [4] define a estrutura interna da árvore como sendo constituída de uma medula central envolvida por anéis de crescimento e recoberta por um tecido especial chamado casca. Entre a casca e o conjunto de anéis de crescimento, chamado lenho, existe uma camada delgada fluida denominada câmbio, que é considerada a parte viva da árvore.

Pereira (2009) [5] afirma que: "Sinteticamente a madeira é um material natural de origem biológica que tem na sua constituição uma matéria heterogênea $e$ anisotrópica“. A heterogeneidade da madeira é a grande a variedade de propriedades entre indivíduos de mesma espécie. A anisotropia trata das diferentes propriedades segundo os três eixos direcionais: longitudinal, radial e tangencial. Pereira (2009) trata da anisotropia da seguinte forma: O comportamento da madeira é descrito por uma simplificação designada por transverso isotrópico que consiste em dizer-se que as propriedades no plano xy (plano paralelo às fibras) são iguais em todas as direções, mas diferem das propriedades apresentadas no plano z (plano perpendicular às fibras).

\subsection{Madeiras no mercado brasileiro}

No ponto de vista da botânica, podem-se dividir em dois grandes grupos: gimnospermas e angiospermas. Dentre as gimnospermas, a conífera é a mais utilizada no mercado brasileiro, com destaque para a pínus e araucárias. No âmbito das angiospermas encontram-se as principais espécies de madeiras duras comercializadas no Brasil. 
Essas duas espécies não diferem apenas no âmbito externo, mas também no âmbito interno. Uma vez que a configuração do seu material lenhoso difere de espécie para espécie. Por isso é importante o estudo sobre a estrutura interna da árvore, acima mencionado.

\subsection{Propriedades físicas e mecânicas da madeira}

Quando se fala do uso de madeiras para o uso como fôrmas de madeira é de extrema importância conhecer as principais madeiras utilizadas na confecção do sistema. As propriedades que devem ser estudadas são: densidade, umidade e retratibilidade. Essas características têm ligações diretas com o tipo de árvore utilizadas na confecção. Esse comportamento é chamado de ortotrópico. Destrinchando o conceito, Nazar [4] afirma que o comportamento ortotrópico é um comportamento diferente em relação à direção das fibras e apresenta os três eixos perpendiculares entre si, considerando a posição das camadas de crescimento dentro da peça longitudinal, radial e tangencial.

\subsection{Sistemas de fôrmas}

Conforme Nazar [4] o sistema de fôrmas pode ser identificado de acordo com os materiais do qual são compostos. Um sistema de fôrmas é o conjunto de materiais e equipamentos que são utilizados para conceber e executar as fôrmas. Em edifícios, os sistemas mais utilizados são o de madeira, metálico e o misto. O critério para utilizar uma ou outra vai depender da peça a ser utilizada, do prazo de execução, da receptividade, e até da disposição econômica da empresa de investir em equipamentos. Para tornar o processo mais eficiente deve-se procurar uma sinergia do projetista da estrutura, o arquiteto, o construtor e o projetista das fôrmas.

\section{METODOLOGIA}

O presente trabalho discorre sobre as manifestações patológicas encontradas em fôrmas de madeira utilizadas em três obras na região metropolitana do Recife. Foi realizada uma visita técnica, com o objetivo de fotografar e identificar os maiores erros cometidos na fabricação e execução das fôrmas e as manifestações patológicas decorrentes destas falhas.

Serão descritas as etapas de execução de cada uma das empresas, que não terão seus nomes citados por motivo de sigilo.

Foi elaborada uma descrição do processo com o objetivo de identificar os principais vícios executados pela mão de obra capacitada, a fim de analisar este processo já tão consolidado no cenário local. Em muitas situações o processo é realizado por repetição e empirismo, que muitas vezes pode gerar erros, uma vez que cada obra possui sua particularidade e uma solução tomada em certo caso não pode ser generalizada.

Através da análise das fotografias e das características destas manifestações patológicas encontradas na construção, foi possível buscar apoio nas bases teóricas como artigos científicos, monografias, dissertações, teses, entre outras fontes bibliográficas sobre o tema estudado, a fim de identificar a manifestação patológica e possíveis soluções. 


\section{RESULTADOS E DISCUSSÕES}

\subsection{Descrições das obras}

Foram descritos três empreendimentos, aqui denominados empreendimento 01,02 e 03. Trata-se de três edifícios de similar situação e característica e que por serem executados por empresas diferentes foram adotadas soluções diferentes.

\subsubsection{Empreendimento 01}

O empreendimento 01 é um edifício multifamliliar com 1 pavimento térreo, 2 vazados e 20 pavimentos tipo. Sendo os 5 primeiros com 8 apartamentos por andar e os demais andares são 6 apartamentos por andar com área entre 18 e $41 \mathrm{~m}^{2}$.

$\mathrm{Na}$ edificação foi utilizado um sistema de fôrmas misto. Os painéis são instalados em obra e constituem de maderito plastificado de $18 \mathrm{~mm}$ com uma estrutura reforçada com sarrafos, também são utilizadas vigas e mãos francesas metálicas para pressionar a fôrmas. A fim de otimizar a utilização do maderito e evitar o corte da folha, foi feita uma alvenaria dobrada, conforme mostram as (Fig. 1 e Fig. 2). Desta forma foi possível evitar cortes desnecessários e aumentar a produtividade da fôrma.

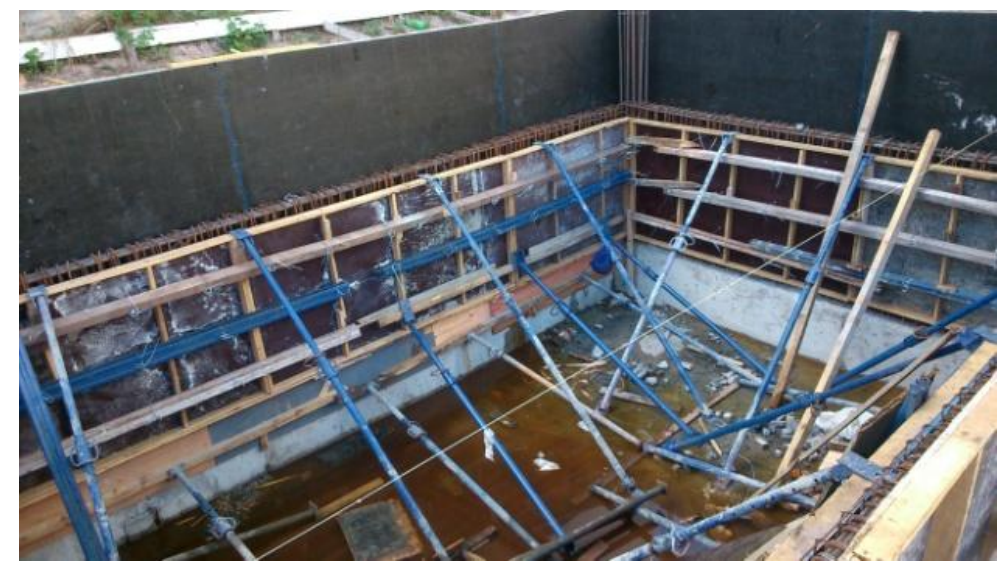

Figura 1: Sistema de fôrmas misto. Painéis de madeiras com estrutura em madeira e escoramento metálico. (Autores, 2016)

As vigas metálicas são amarradas com arames em distância de mais ou menos 50 $\mathrm{cm}$ de uma amarração para outra, conforme experiência dos carpinteiros. Houve nas estruturas de concreto onde foram utilizadas as fôrmas fabricadas em obra a falta de retilinidade ou desaprumo das fôrmas das paredes, cavidades devidas às saliências ou ondulações das fôrmas. A situação foi recorrente e verificada na maioria das peças concretadas. 


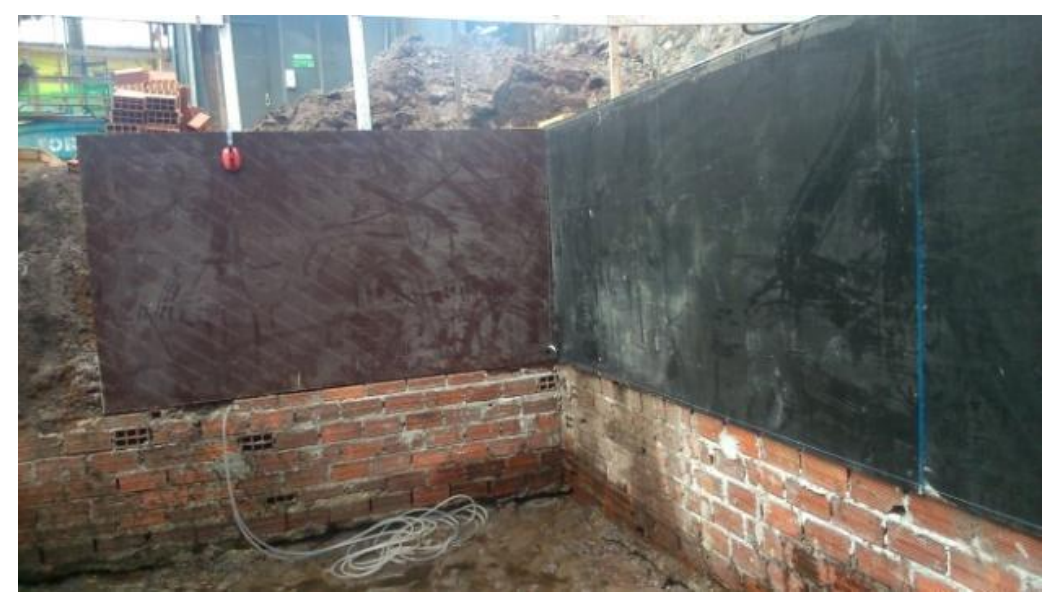

Figura 2: Sistema misto de alvenaria e madeira. (Autores, 2016)

\subsubsection{Empreendimento 02}

O empreendimento 02 é um edifico multifamiliar, com 02 pavimentos vazados, 29응 pavimentos tipos que apresentam variações, coberta e ático. A obra encontra-se na fase da estrutura, concretando os pavimentos tipo.

O empreendimento 02 possui 14 carpinteiros e 7 serventes, e executam 4 lajes por semana, considerado um ritmo acelerado de produção. Foi utilizado o sistema de fôrmas prontas, onde os carpinteiros só realizam a montagem na obra, o sistema vinha racionalizado para a melhor utilização. A fôrma em madeira com os escoramentos das lajes metálicos e o escoramento das vigas em madeira.

Foram encontrados desaprumo de vigas, pilares de maneira bem pontual. Não foram identificadas grandes manifestações patológicas decorrentes da utilização de fôrmas.

\subsubsection{Empreendimento 03}

O empreendimento 03 é um edifício multifamiliar composto por 25 pavimentos tipos, com dois apartamentos por andares, três elevadores. Situado no bairro do Rosarinho, zona Norte do Recife. A obra possui 4 carpinteiros e 4 ajudantes. Com uma laje de área igual a $308 \mathrm{~m}^{2}$, sendo executadas duas lajes por semana em um ritmo de trabalho considerado lento. Foi adotado nesta obra o sistema de fôrmas prontas com fôrmas em madeira, escoramentos metálicos para as lajes e escoramentos em madeira para as vigas.

No empreendimento 03 encontra-se uma situação semelhante ao empreendimento 02, não foram identificadas grandes manifestações patológicas decorrente da utilização de fôrmas. Mas foi verificado o desaprumo de peças estruturais.

\subsection{Análises das manifestações patológicas}

\subsubsection{Empreendimento 01}

No empreendimento 01 foi analisada a concretagem do reservatório inferior do edifício. O sistema de fôrmas utilizado na concretagem foi misto de alvenaria e 
fôrma tradicional. Onde a alvenaria foi utilizada, existiam falhas no recobrimento, sendo necessário um tratamento com graut. A (Fig. 3) demonstram a armação desprotegida. O tratamento foi feito imediatamente após a desfôrma, aplicando-se o grout nos locais onde a armação ficou exposta. Foi ainda identificado desaprumo e o embuxamento das paredes do reservatório, conforme a (Fig. 4).

A linha vermelha deixa o desaprumo evidente na foto, este foi causado pelo conjunto concreto e vibração, exercendo força excessiva nas paredes, causando assim o desaprumo. O dimensionamento não levou em consideração uma base cientifica, considerou apenas o empirismo e experiências dos profissionais participantes do processo de montagem da fôrma, o que explica a falta de resistência do conjunto de fôrmas. A armazenagem das fôrmas (Fig. 5) é executada de qualquer maneira, sem respeitar a integridade do material.

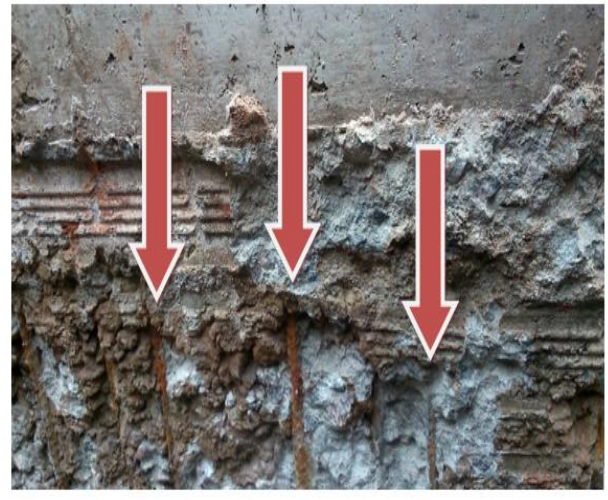

Figura 3: Concreto lançado na alvenaria. A seta vermelha indica onde o aço ficou a mostra. (Autores, 2016)

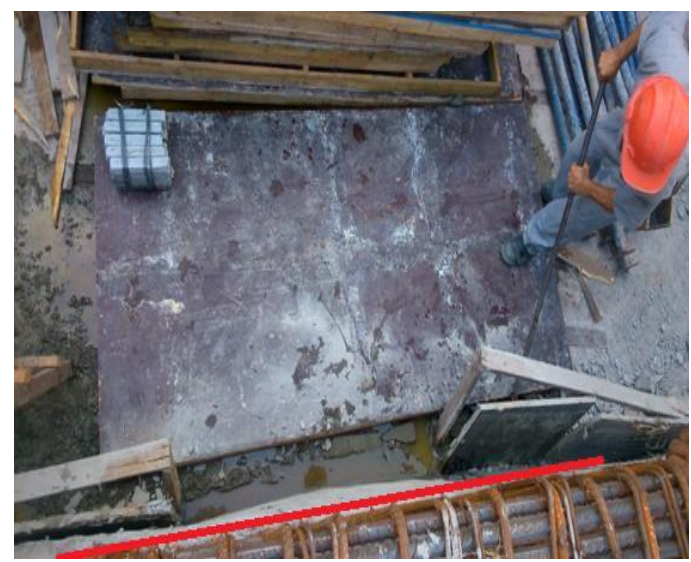

Figura 4: Momento da desfôrma das paredes do reservatório, a linha vermelha indica o embuchamento da estrutura de concreto. (Autores, 2016)

Desta forma os painéis diminuem em muito a sua vida útil, aumentando o gasto na obra com madeira e maderitos. 


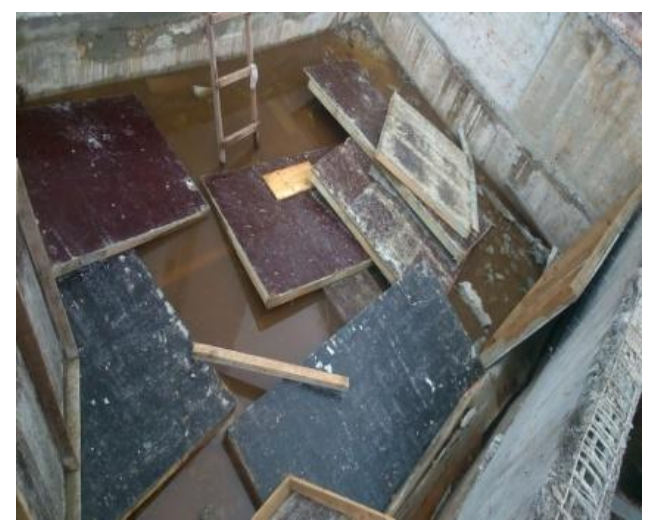

Figura 5: Fôrmas depositadas dentro d’água. (Autores, 2016)

\subsubsection{Empreendimento 02}

O empreendimento 02 foi visitado na concretagem da $17^{\mathrm{a}}$ laje. Não foram verificados erros sérios na montagem da fôrma, encontrando-se apenas desaprumos pontuais nas vigas. A (Fig. 6) mostra a estrutura do empreendimento 02. A (Fig. 7) mostra o escoramento do fundo da viga.

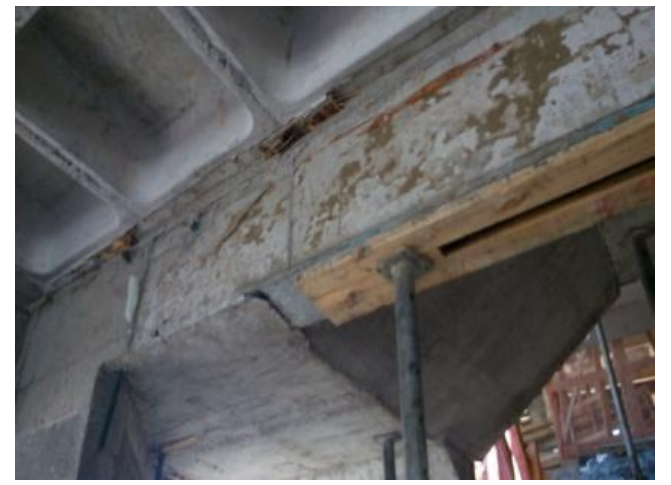

Figura 6: Laje do empreendimento 02 com as faixas de reescoramentos. (Autores, 2016)

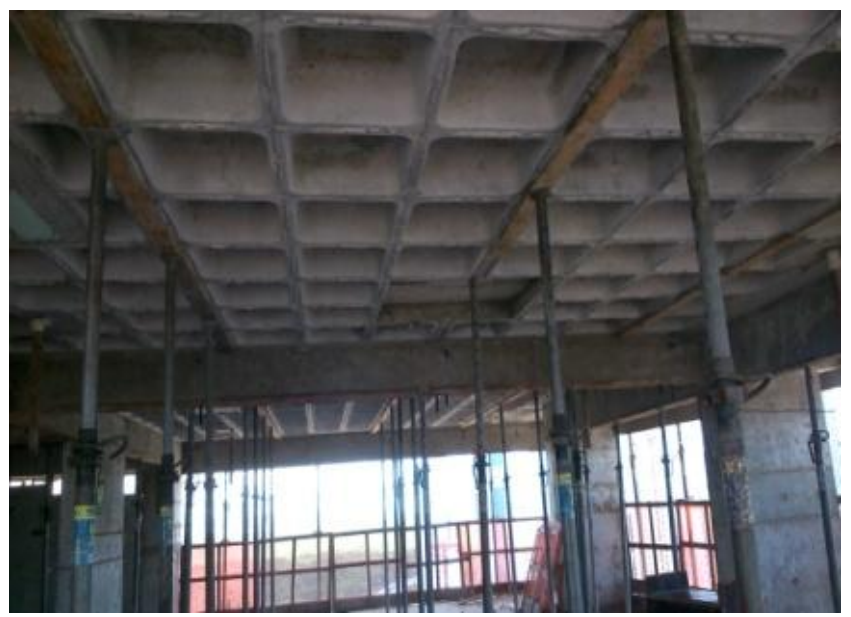

Figura 7: Fôrmas do fundo da viga junto com escoramento metálico. (Autores, 2016) 


\subsubsection{Empreendimento 03}

O empreendimento 03 possui uma situação semelhante ao empreendimento 02 . É utilizado o sistema de fôrmas prontas e uma equipe experiente verifica uma montagem correta do sistema. As fôrmas foram bem dimensionadas, pois uma empresa especializada foi responsável pela elaboração do projeto, embora tenham sido encontrados com mais frequências manifestações patológicas decorrentes da má utilização da fôrma de madeira. Mesmo com um sistema adequadamente projetado, faltou uma eficiente fiscalização em algumas etapas.

A (Fig. 8) demonstra um desalinhamento da viga do empreendimento que foi ocasionado pela falha na conferência durante a concretagem, uma vez que 0 esforço do mangote vibrador do concreto exerce uma força que muitas vezes não foram consideradas na etapa de projeto do sistema de fôrmas. Durante a execução da concretagem é importante o acompanhamento do concreto, pois é comum que o esforço do mangote desalinhe a viga e a correção durante a concretagem é indispensável. A (Fig. 9) demonstra um leve desalinhamento na marquise, provocado no momento da desfôrma, a reescora deve ser executada imediatamente. A (Fig. 10) demonstra um leve desalinhamento na união da viga com o pilar.

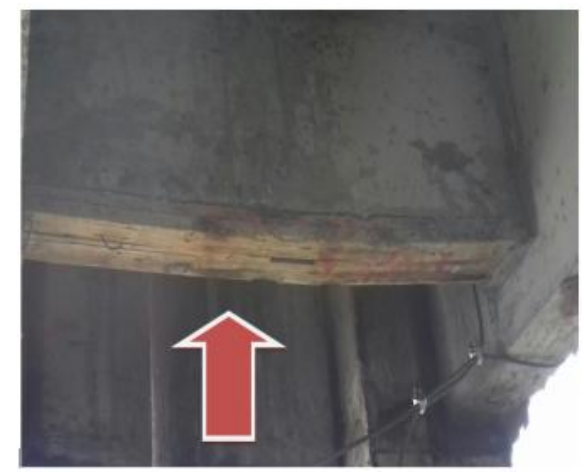

Figura 8: Desalinhamento da viga indicado pela seta vermelha. (Autores, 2016)

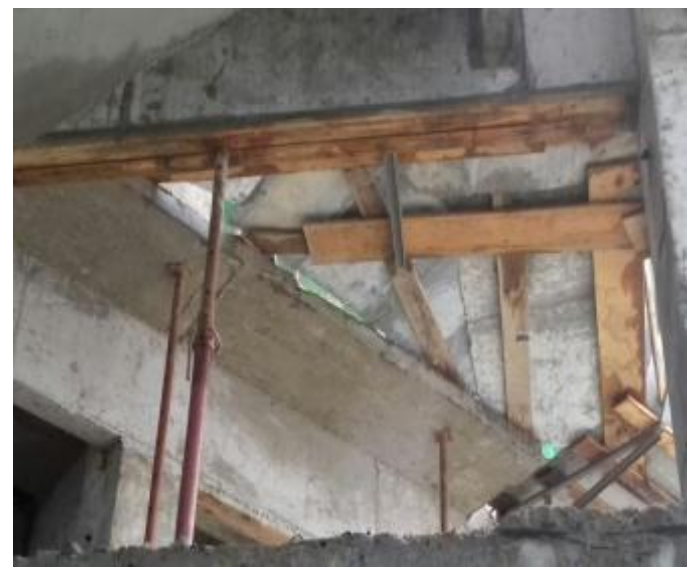

Figura 9: Desalinhamento da marquise. (Autores, 2016) 


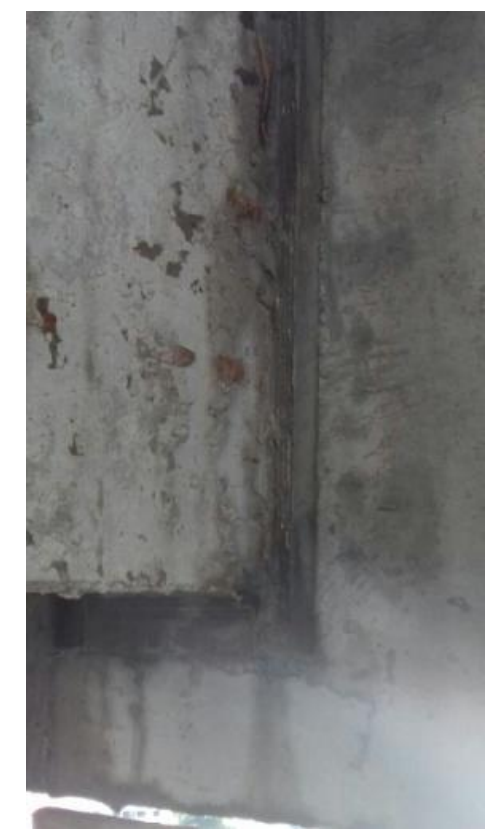

Figura 10: Viga com leve desalinhamento no contato com um pilar. (Autores, 2016)

\section{Considerações finais}

Pode-se concluir que na edificação 02 onde existiu um projeto de sistema de fôrmas dimensionado e detalhado por profissionais compentente aliado a uma forte fiscalização no momento da montagem e da desfôrma, as manifestações patológicas encontradas foram mínimas.

$\mathrm{Na}$ edificação 03, não houve uma fiscalização e atenção adequada na montagem do sistema de fôrmas. A partir disto é possível concluir que mesmo com um projeto bem elaborado, a falta de fiscalização e montagem inadequada do sistema são responsáveis pelas falhas encontradas.

$\mathrm{Na}$ edificação 01 , o sistema de fôrmas foi dimensionado pelos trabalhadores da construção, que não possuiam conhecimento técnico adequado para tal dimensonamento. Foram encontradas diversas falhas que são justificadas pela falta de projeto elaborado por profissionais qualificados.

A partir da análise destes resultados, é possível concluir que um projeto de sistema de fôrmas dimensionado e elaborado da forma correta unido a uma fiscalização adequada durante a montagem e desfôrma é capaz de evitar as manifestações patológicas mais comuns decorrentes desses sistemas.

\section{Agradecimentos}

O desenvolvimento deste artigo é de grande relevância para a comunidade acadêmica e não seria possível sem a colaboração de todos os participantes que se fizeram presentes durante sua construçao. Agradecemos a todos os envolvidos

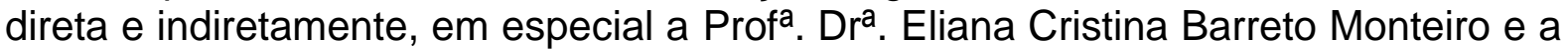
Universidade Católica de Pernambuco. 


\section{Referências}

[1] Associação brasileira de normas técnicas (2009). NBR 15696 - Fôrmas e escoramentos para estruturas de concreto - Projeto, dimensionamento e procedimentos executivos. Rio de Janeiro: ABNT.

[2] Moreschi, João Carlos. (2012). Propriedades da madeira. Disponível em: $<$ http://www.madeira.ufpr.br/disciplinasmoreschi/propriedadesdamadeira.pdf>. Acesso em: 03/04/2018.

[3] Müller, Guilherme Luiz. (2016). Dimensionamento de fôrmas de madeira para estruturas de concreto armado: uma proposta teórica (Graduação) - Centro Universitário UNIVATES.

[4] Nazar, Nilton. (2007). Fôrmas e escoramentos para Edificações: critérios para dimensionamento e escolha do sistema. Pini.

[5] Pereira, Samuel Soares Camarinha. (2009). Avaliação Experimental das principais propriedades mecânicas de peças estruturais em madeira antiga. (Mestrado) - Faculdade de Engenharia, Universidade do Porto.

[6] Rodrigues, Menandro Alison Sales; Sales, Juscelino Chaves. (2013). A madeira e suas patologias. Estudo de caso: Igreja Nossa Senhora das Mercês Itapipoca/CE. In: Congreso Internacional sobre Patología y Recuperación de Estructuras. João Pessoa. 